\title{
Masturbation is Related to Psychopathology and Prostate Dysfunction: Comment on Quinsey (2012)
}

\author{
Rui Miguel Costa
}

Published online: 12 April 2012

(c) Springer Science+Business Media, LLC 2012

In an interesting discussion about which criteria should guide the diagnoses of paraphilias, Quinsey (2012) observed that "in order for a condition to be considered a mental disorder, the condition must represent the failure of some mental mechanism to perform the function for which it was designed by natural selection and the condition must cause some deprivation of benefit (defined in terms of the society within which the affected individual lives)" (p. 218). Furthermore, it is noted that, from an evolutionary perspective, a deprivation of benefit should carry costs of reduced fitness (Quinsey, 2012).

Consequently, Quinsey concluded that most actual and proposed DSM paraphilias do not clearly meet these criteria, because it is not clear if they diminish reproductive fitness by reducing the likelihood of penile-vaginal intercourse (PVI) with fertile partners. In so doing, he offers the example of masturbation as being a healthy behavior that appears to have no such interference. He asserted that masturbation is healthy by "for example, lessening the likelihood of developing prostate cancer, improving mood, developing sexual interests, and perhaps even ridding oneself of tired sperm" (p. 219). However, these unreferenced claims contrast sharply with the best available empirical evidence.

It is difficult to reconcile the view that masturbation improves mood with the findings in both sexes that greater masturbation frequency is associated with more depressive symptoms (Cyranowski et al., 2004; Frohlich \& Meston, 2002; Husted \& Edwards, 1976), less happiness (Das, 2007), and several other indicators of poorer physical and mental health, which include anxious attachment (Costa \& Brody, 2011), immature psychological defense mechanisms, greater blood pressure reactivity to stress, and dis-

R. M. Costa (更)

ISPA-Instituto Universitário, Unidade de Investigação em Eco-Etologia, Rua do Jardim do Tabaco 34, 1149-041 Lisbon, Portugal

e-mail: rmscosta@gmail.com satisfaction with one's mental health and life in general (for a review, see Brody, 2010). It is equally difficult to see how masturbation develops sexual interests, when greater masturbation frequency is so often associated with impaired sexual function in men (Brody \& Costa, 2009; Das, Parish, \& Laumann, 2009; Gerressu, Mercer, Graham, Wellings, \& Johnson, 2008; Lau, Wang, Cheng, \& Yang, 2005; Nutter \& Condron, 1985) and women (Brody \& Costa, 2009; Das et al., 2009; Gerressu et al., 2008; Lau, Cheng, Wang, \& Yang, 2006; Shaeer, Shaeer, \& Shaeer, 2012; Weiss \& Brody, 2009). Greater masturbation frequency is also associated with more dissatisfaction with relationships and less love for partners (Brody, 2010; Brody \& Costa, 2009). In contrast, PVI is very consistently related to better health (Brody, 2010; Brody \& Costa, 2009; Brody \& Weiss, 2011; Costa \& Brody, 2011, 2012), better sexual function (Brody \& Costa, 2009; Brody \& Weiss, 2011; Nutter \& Condron, 1983, 1985; Weiss \& Brody, 2009), and better intimate relationship quality (Brody, 2010; Brody \& Costa, 2009; Brody \& Weiss, 2011).

Moreover, although less risk of prostate cancer was associated with greater number of ejaculations (without specification of the sexual behavior) (Giles et al., 2003), it is PVI frequency that is specifically associated with reduced risk, whereas masturbation frequency is more often related to increased risk (for a review on the subject, see Brody, 2010). In this regard, it is interesting to note that masturbation is also associated with other problems of the prostate (higher prostate specific antigen levels and swollen or tender prostate) and, compared with the ejaculate obtained from PVI, the ejaculate obtained from masturbation has markers of poorer prostatic function and lesser elimination of waste products (Brody, 2010).

The only sexual behavior consistently related to better psychological and physical health is PVI. In contrast, masturbation is frequently associated with indices of poorer health (Brody, 2010; Brody \& Costa, 2009; Brody \& Weiss, 2011; Costa \& Brody, 2011, 2012). There are several possible psychological and physiological mechanisms, which are a likely consequence 
of natural selection favoring health processes as cause and/or effect of motivation to search for, and capacity to obtain and enjoy, PVI. In contrast, selection of psychobiological mechanisms rewarding motivation to masturbate is unlikely due to the severe fitness costs that would occur if it deterred one from PVI by making it irrelevant for well-being (Brody, 2010). More plausibly, masturbation represents some failure of the mechanisms of sexual drive and intimate relatedness, however common it may be, and even if not uncommonly it coexists with access to PVI. In this regard, it is noteworthy that greater masturbation frequency is associated with dissatisfaction with several aspects of life independently of PVI frequency (Brody \& Costa, 2009) and seems to diminish some benefits of PVI (Brody, 2010). In sum, the analogy with masturbation does not strengthen the view that paraphilias do not reduce reproductive fitness.

A final remark relates to Quinsey's observation that homosexuality may increase inclusive fitness through investment in genetic relatives by referring to findings in Samoan homosexual men (Vasey \& VanderLaan, 2010). However, it was noted that, if such adaptation to support kin had evolved, a very strong effect would have to be apparent in the fitness of siblings (which is not demonstrably the case) and asexuality might be a better adaptation to divert resources from mating to care for siblings (Miller, 2000). Furthermore, studies in the West showed that homosexual men do not invest more in family members than heterosexual men, the opposite being actually observed (Bobrow \& Bailey, 2001; Rahman \& Hull, 2005). Even if some forms of male homosexuality are, at least in part, genetically determined, the genes relevant for homosexuality could survive, if they contributed to characteristics that increase the attractiveness and parental care of some heterosexuals, such as kindness, empathy, and tendermindedness in men (Miller, 2000). This explanation could also apply to female homosexuality, if some heterosexual women increased their reproductive success due to the presence of some more masculine traits with genetic origin (Miller, 2000).

\section{References}

Bobrow, D., \& Bailey, J. M. (2001). Is male homosexuality maintained via kin selection? Evolution and Human Behavior, 22, 361-368.

Brody, S. (2010). The relative health benefits of different sexual activities. Journal of Sexual Medicine, 7, 1336-1361.

Brody, S., \& Costa, R. M. (2009). Satisfaction (sexual, life, relationship, and mental health) is associated directly with penile-vaginal intercourse but inversely with other sexual behavior frequencies. Journal of Sexual Medicine, 6, 1947-1954.

Brody, S., \& Weiss, P. (2011). Simultaneous penile-vaginal intercourse orgasm is associated with satisfaction (sexual, life, partnership, and mental health). Journal of Sexual Medicine, 8, 734-741.
Costa, R. M., \& Brody, S. (2011). Anxious and avoidant attachment, vibrator use, anal sex, and impaired vaginal orgasm. Journal of Sexual Medicine, 8, 2493-2500.

Costa, R. M., \& Brody, S. (2012). Greater resting heart rate variability is associated with orgasms through penile-vaginal intercourse, but not with orgasms from other sources. Journal of Sexual Medicine, 9, 188-197.

Cyranowski, J. M., Bromberger, J., Youk, A., Matthews, K., Kravitz, H. M., \& Powell, L. H. (2004). Lifetime depression history and sexual function in women at midlife. Archives of Sexual Behavior, 33, 539-548.

Das, A. (2007). Masturbation in the United States. Journal of Sex and Marital Therapy, 33, 301-317.

Das, A., Parish, W. L., \& Laumann, E. O. (2009). Masturbation in urban China. Archives of Sexual Behavior, 38, 108-120.

Frohlich, P., \& Meston, C. (2002). Sexual functioning and self-reported depressive symptoms among college women. Journal of Sex Research, $39,321-325$.

Gerressu, M., Mercer, C. H., Graham, C. A., Wellings, K., \& Johnson, A. M. (2008). Prevalence of masturbation and associated factors in a British national probability survey. Archives of Sexual Behavior, 37, 266-278.

Giles, G. G., Severi, G., English, D. R., McCredie, M. R., Borland, R., Boyle, P., et al. (2003). Sexual factors and prostate cancer. BJU International, 92, 211-216.

Husted, J. R., \& Edwards, A. E. (1976). Personality correlates of male sexual arousal and behavior. Archives of Sexual Behavior, 5, 149_ 156.

Lau, J. T., Cheng, Y., Wang, Q., \& Yang, X. (2006). Prevalence and correlates of sexual dysfunction among young adult married women in rural China: A population-based study. International Journal of Impotence Research, 18, 89-97.

Lau, J. T., Wang, Q., Cheng, Y., \& Yang, Y. (2005). Prevalence and risk factors of sexual dysfunction among younger married men in a rural area in China. Urology, 66, 616-622.

Miller, E. M. (2000). Homosexuality, birth order, and evolution: Toward an equilibrium reproductive economics of homosexuality. Archives of Sexual Behavior, 29, 1-34.

Nutter, D. E., \& Condron, M. K. (1983). Sexual fantasy and activity patterns of females with inhibited sexual desire versus normal controls. Journal of Sex and Marital Therapy, 9, 276-282.

Nutter, D. E., \& Condron, M. K. (1985). Sexual fantasy and activity patterns of males with inhibited sexual desire and males with erectile dysfunction versus normal controls. Journal of Sex and Marital Therapy, 11, 91-98.

Quinsey, V. L. (2012). Pragmatic and Darwinian views of the paraphilias. Archives of Sexual Behavior, 41, 217-220.

Rahman, Q., \& Hull, M. S. (2005). An empirical test of the kin selection hypothesis for male homosexuality. Archives of Sexual Behavior, 34, 461-467.

Shaeer, O., Shaeer, K., \& Shaeer, E. (2012). The Global Online Sexuality Survey (GOSS): Female sexual dysfunction among internet users in the reproductive age group in the Middle East. Journal of Sexual Medicine, 9, 411-424.

Vasey, P. L., \& VanderLaan, D. P. (2010). Avuncular tendencies and the evolution of male androphilia in Samoan fa'afafine. Archives of Sexual Behavior, 39, 821-830.

Weiss, P., \& Brody, S. (2009). Female sexual arousal disorder with and without a distress criterion: Prevalence and correlates in a representative Czech sample. Journal of Sexual Medicine, 6, 3385-3394. 